\title{
Descartes in a 'Headstand': Introducing 'Body-Oriented Pedagogy'
}

\author{
OREN ERGAS \\ Hebrew University of Jerusalem
}

\begin{abstract}
This article's main theme is the conceptualization of a 'body-oriented-pedagogy' that unfolds a possible account of 'bow one learns from the body'. Based on B.K.S Iyengar's approach to yoga-posture practice, which is embedded in classical yoga's philosophy of 'mind', a 'body-oriented pedagogy' is depicted as a practice that seeks to incite 'embodied mindfulness'. The pedagogy trains one in turning 'body' into 'subject', thus quieting the 'thinking mind'. It is thus conceptualized as turning the Cartesian crowning of 'mind' over 'body' upside down. This pedagogy is suggested as yielding 'education towards and in presence'. Presence is characterized as a mode of perceiving experience prior to the grid of language and concepts, enhancing one's ability to choose one's action. Applying the grounding of pedagogy in 'body', the article then contributes to the discourse involved in the incorporation of contemplative practice within schooling. 'Body-oriented pedagogy' is depicted as compatible with both 'spiritual' and 'non-spiritual' curriculum orientations.
\end{abstract}

\section{Introduction}

In the past decades, contemplative practices from Eastern traditions have become well-noticed within Western industrialized countries. Various forms of yoga and meditation are being explored in a plethora of disciplines within the academic world, including neuroscience (Davidson et-al., 2003), psychology (Kabat-Zinn, 2005) and, particularly concerning this article, education (Miller, 2007, Eppert \& Wang, 2008). However, the incorporation of contemplative practices in Western curricula is still a relatively marginal phenomenon. This article contends that one reason for this marginality is that we have not yet developed a rigorous conceptualization of contemplative practice as pedagogy, with a specific concern as to the role of the body within such pedagogy. Some scholars have assessed the effects of the incorporation of some contemplative practices in education (Napoli, Krech \& Holey 2005, Flook et-al., 2010). However, a complete focus on effects cannot supply a full justification for an educational practice. Dewey (1916), Bruner (1960), Eisner (1993) and many others characterized education as a process rather than as a means/ends endeavor. Contemplative practices and their effects are many and varied; nevertheless we must provide an elaborate understanding of the educational process they invoke if we wish to justify their place within the curriculum. That is, if we wish to incorporate yoga, taiqi, mindfulness practice, prayer, guided visualizations, nature walks or other forms of contemplative practice, our curriculum theory cannot settle for accounts of what the effects of such practices are. It must also address the question how one learns by engaging in any one of these practices.

This article addresses this need through interpreting yoga posture practice as an example of a 'body-oriented pedagogy'. I present 'body-oriented pedagogy' as a process that seeks to incite 'embodied mindfulness' (Johnson, 2000) based on the philosophy of ancient classical yoga and on contemporary yoga teacher B.K.S. Iyengar's approach to posture practice. 'Embodied mindfulness' is a dwelling within a pre-conceptual knowing based on acute awareness to sensations. I propose that this pre-conceptual state of sensing 'body' cultivates the yoga practitioner's discernment of how 'mind' operates. 'Body-oriented pedagogy' thus places 'Descartes in a headstand' by reversing the Cartesian hierarchy of 'mind' over 'body'

(C) Copyright 2013. The author, Oren Ergas, assigns to Paideusis the right of first publication and educational and non-profit institutions a non-exclusive license to use this document for personal use and in courses of instruction provided that the article is used in full and this copyright statement is reproduced. Any other usage is probibited without the express permission of the author. 
and allocating 'body' a privileged status over 'mind'. That is, proper practice asks the 'mind' to attend to bodily sensations and skillfully respond to (even obey) them by constantly adjusting the posture according to the moment's needs. This occurs at the expense of the "chattering mind" barging in to express its judgmental nature as it constantly tends to evaluate the body's performance by assuming an external point of view. 'Body-oriented pedagogy' yields 'education towards and in presence', which cultivates knowledge of why we behave as we do. It enhances our ability to choose our actions as the motivations underlying them become more transparent to us.

Zooming out from the realm of pedagogy to the realm of its embedding within a social setting, this article subsequently reflects on the incorporation of 'body-oriented pedagogy' within schools. While Heelas \& Woodhead (2005) view the pervasiveness of contemplative practices (among other factors) as a 'spiritual revolution', the approach taken here presents 'body-oriented pedagogy' as lending itself to both 'spiritual' and 'non-spiritual inclinations on the one hand, or as foregoing the framing "game" as such.

The article develops three main themes. First, I will introduce the philosophy of classical yoga as the origin of 'body-oriented pedagogy', and discuss the terms 'mind' and 'body' in contrast to a more familiar Cartesian body/mind dualism. Second, I will describe 'body-oriented pedagogy' and 'embodied mindfulness', concentrating mostly on how one might learn from the 'body', and briefly on how 'education towards and in presence' might emerge from such pedagogy. Finally, I will discuss the relations between 'body-oriented pedagogy' and 'spirituality' suggesting a pragmatic discursive strategy that should increase the chances that 'body-oriented pedagogies' will be included within school curricula.

\section{Classical Yoga and Mindfulness}

The term 'yoga' is defined by Feuerstein (2001) as "the generic name for the various Indian paths of ecstatic self-transcendence, or the methodical transmutation of consciousness to the point of liberation from the spell of the ego-personality" (p. 6). Adopting this conception, Buddhism, Zen, Taoism and Hinduism can all be considered forms of yoga, as any one of these traditions has focused on the unraveling of the nature of "self" and its liberation. Classical yoga is one of six schools of thought constituting Hinduism (Feuerstein, 2001, p. 72). It is based on Patanjali's yogasutra, condensed arguably around the 2nd century CE (p. 214). This short text includes 196 aphorisms and is a philosophicalpractical guide for one who seeks 'Self-realization' (Iyengar, 1993, p. 3); a term we may think of as implying a version of 'enlightenment'. Self here does not refer to ego-self, but rather to an undifferentiated consciousness. While I shall clarify what is meant by Self-realization more fully later on, describing this state in detail is beyond the scope of this article. My concern is rather with the process towards this realization through one aspect of classical yoga, namely, the yogic posture. Given that this article emphasizes an understanding of the body's pedagogical potential, in the following, I explain how 'body' and 'mind' are conceived in classical yoga, and how they are related to enlightenment. I begin, though, with a discussion of Descartes' formulation of the 'body'/'mind' dualism as a more familiar starting point from which to explore classical yoga's less intuitive formulation.

Descartes' motivation for his meditations was the establishment of certainty. ${ }^{1}$ Employing a method of radical doubt, the only thing he deemed certain was his own existence as doubter. Thus he declares: "But what then am I? A thing that thinks..." (1988, p. 83). Descartes established the human subject as 'a thinking thing' (res cogitans). He attributed the faculty of thinking to 'mind'. Conversely, the adherence to 'mind' was the shunning away from 'body' which represented the senses and the emotions. The latter were to be avoided as sources for certain knowledge, given that they led Descartes to error in past cases, as he testified. ${ }^{2}$ The Cartesian worldview thus not only established a dichotomy between mind and body, it also posed a clear hierarchy placing 'mind' superior to 'body'.

Classical yoga views answering the question 'who am I?' as the only final remedy for a human condition that it defines as one of suffering. ${ }^{3}$ The solution to suffering it proposes assumes a radically

\footnotetext{
${ }^{1}$ Descartes: "I realized that it was necessary, once in the course of my life, to demolish everything completely and start again right from the foundations if I wanted to establish anything at all in the sciences that was stable and likely to last." (1988, p. 76 italics mine).

2 "Thus, because our senses sometimes deceive us, I decided to suppose that nothing was such as they led us to imagine." (1988, p. 36)

${ }^{3}$ Refer to Patanjali's sutra (II.15):"...to the discerner all is but suffering (dukkha)".
} 
different subject/object dualism than the one proposed by Descartes. This dualism is rendered diversely by yoga interpreters as Self/Nature (Feuerstein, 2001, p. 242), Spirit/Nature (Eliade, 2009), or Soul/Nature (Iyengar, 2005). In any case[,] the terms Self/Spirit/Soul here all refer to the pure subject, our Absolute and authentic identity, and I will be applying them according to the interpreter to which I refer. In this dualistic system, we are considered to be a marriage of an absolute Soul (Spirit/Self) and Nature (Iyengar, 2005, p. 9). Our 'mind' and 'body' and their corresponding thoughts, sensations, feelings and emotions, however, are considered objects and are referred to as pertaining to Nature. That is, they are not to be confused as our authentic identity within Soul. To begin understanding this claim let us look at Feuerstein's definition of classical yoga's Self as: "...the transcendental Self, Spirit, or pure Awareness, as opposed to the finite personality" (2001, p. 458). The 'finite personality' has nothing to do with this Self/Spirit/Soul (depending on the interpreter). It is rather one manifestation of the objective phenomenal world. However, in the ordinary unenlightened day-to-day, the 'finite personality' is who we experience ourselves to be. It consists of the constant flux of our thoughts, sensations, feelings, emotions and so forth; all considered objects according to classical yoga. As Eliade (2009, p. 15) points out, these mental objects are not substantially different than what we take to be tangible objects, such as the paper you may be holding or the desktop towards which your gaze is directed.

There are two reasons why the idea that mental and tangible objects are made of the same fabric may be difficult to fathom: Firstly, this suggests a stark contrast to a Cartesian view described above, which seems much more intuitive. How can thoughts possibly be compared with a table, for example? Or even with the sensation of touching a table? Secondly, and perhaps more challenging, both sensations and thoughts according to classical yoga do not reflect our authentic identity. They are conceived as pertaining to Nature (the object), which has nothing to do with the subject. Thus, they are essentially impersonal and should not serve as a source for our identity. Like Descartes, we tend to think that if there is a thought "in" our mind then there is an I that thinks it. Yet, Descartes' answer to the question 'who I am'; namely, "I am a thinking thing" would be considered by classical yoga to be a fatal mistake and, in fact, the buman predicament. The fact that we tend to constantly think does not lead necessarily to claiming that we are a "thing". Classical yoga would suggest that our thinking in fact places a curtain over our true identity. In such case, the more we cling to a Cartesian subject the less chance we have of realizing who we truly are. However, we tend to believe otherwise. When we say "I am hungry," "I am angry," or "I am happy," we wrongfully believe this 'I' to be who we are. ${ }^{4}$ Classical yoga does not ignore the validity of such psycho-physical experiences. It rather states that beyond them lies an unchanging Self/Spirit/Soul that can never be hungry or angry. Such ephemeral states cannot be a source for a stable identification. The goal of classical yoga is to realize Self/Spirit/Soul as our only truthful identity; to understand that one is neither fully one's thoughts, nor one's sensations. Stated in Cartesian language, this implies: I am neither 'body' nor 'mind'. I am certainly not only, or primarily, 'a thinking thing'.

It is quite counter-intuitive that classical yoga, especially in its modern rendition of postural yoga (De Michelis, 2004), turns to the 'body' as a means towards non-dualistic realization. The puzzle is twofold: First, it is not quite clear how 'body', which pertains to Nature, will allow us to leap off to a different realm within Self; a problem classical yoga leaves somewhat unsolved (Eliade, 2009, p. 18). Second, s the Western philosophical tradition from Plato's phaedo to Descartes' meditations insisted that relying on the 'body' taints our perception. In stark contrast, , classical yoga, especially as interpreted by Iyengar $(2002,2005)$ - suggests that 'body' is an Archimedean point from which knowledge, in fact redemptive knowledge, can be attained. ${ }^{5}$ The 'body' is an initial gross pre-conceptual mode from which we can later handle the subtler aspects of 'mind' and eventually realize Soul (Iyengar, 2005 pp. 11-12). In fact, 'mind', which will later be defined more clearly through classical yoga philosophy, is untrustworthy as long as it is left untrained by yogic practice. This constitutes a reversal of the Cartesian body/mind dualism, which viewed any knowledge emerging from the 'body' as doubtful. In order to explain this claim, however, we need to delve deeper into classical yoga's philosophy of 'mind'.

Classical yoga interprets 'mind' as three components working in concert. Roughly described, the first of these components is, 'lower' mind, which is the organ related to our perception. It gathers sense data, thinks and decides, yet at a rather crude level. It is considered a sixth sense, with thoughts being its

\footnotetext{
${ }^{4}$ Iyengar (2005, p. 118): "...every time we say the word 'I,' we feel something hard and monolithic inside us, like a great stone idol."

${ }^{5}$ Iyengar (2002, p. 46): "... within the one discipline of asana [posture] all the eight levels of yoga are involved, from yama and niyanma, through to Samadhi."
} 
objects. Then there is 'higher' mind, which is considered the 'intellect' or 'reason,' and allows insight, reflection, and discrimination. Finally, there is the I-maker, which personalizes the experiences of the previous two components. The combination of the above triplex forms an illusory sense of egopersonality (not Self/Spirit/Soul) as I shall now explain. ${ }^{6}$

Nature, as the objective phenomenal world to which 'mind', 'body' and their manifestations as thoughts, sensations, emotions, feelings pertain, is in constant flux. 'Mind' reflects this restless flux directly. We experience 'mind' as thoughts and sensations, for example, evoked by the three components of 'mind': The 'lower' mind yields inner and outer stimuli that are respectively thoughts and sense-data received from the sensing organs (Iyengar, 2005, p. 113). At the same time, the I-maker personalizes these experiences, creating the sense that they are our experiences. This creates the false identity of a permanent 'I', while, in fact, that which is the source of this 'I' is impersonal Nature, given that it is one aspect of 'mind'.7 Our problem, according to classical yoga, is that we take what is in fact object (Nature) to be subject. It is only when the third component of 'higher mind' (intellect) enters the picture that the discrimination between subject and object becomes possible. While I interpret this 'entrance into the picture' as the quality of mindfulness based on Iyengar (2005, pp. 123-4) and Eliade (2009, p. 27), I apply Johnson's (2000) term 'embodied mindfulness' in order to stress the presence of 'body' within the practice described. Johnson's term allows an ambiguity that I view as a more faithful expression both of classical yoga philosophy and of the practice described. Based on the above theoretical framework, I can now progress to describe 'body-oriented pedagogy' unraveling how we can learn from the body.

\section{The Yogic Asana as 'Body-Oriented Pedagogy'}

The yogic posture is the third of eight stages (limbs) constituting the full classical yogic practice (Yogasutra II.29).8 Patanjali, the author of the yogasutra, does not mention any specific posture in his text. Such elaborations are part of much later texts (e.g, Hatha Yoga Pradipika, Gheranda Samhita), and the living body of knowledge transferred from guru to disciple since ancient times. B.K.S. Iyengar, considered perhaps one of the most renowned yogis of our times, is a living example of this long lineage. Beginning practice as a young and sickly child, Iyengar developed his system through great perseverance and insight, bringing his approach to Europe and North America since the 1950s. Iyengar is currently in his nineties, still practicing rigorously on a daily basis (Iyengar, 2005).

The focal point I address here lies in what Iyengar describes as the "first lesson yoga teaches," which is: "...you have to learn to treat...the body as a subject" (2002, p. 94). Let me elaborate with an example of a common yogic posture, which will later enable us to grasp the philosophical argumentation much more clearly.

Let us take a posture such as the following intense back stretch, which looks like this may be familiar to some of us from our physical education lessons. However, most of us probably look

more like this when performing it (compare both the angle between the back and the legs, and how far each figure is able to reach out with his/her hands). Let us call the guy above Joe, and the woman, Karen. The juxtaposition between these two illustrations will clarify Iyengar's interpretation of practice.

Judged merely by looking at these two pictures, if we thought of taking yoga lessons, we would probably turn to Joe rather than to Karen. Karen seems like she needs some practice, while Joe seems like an accomplished practitioner. This first impression would quickly change if we were informed that when Joe woke up the next morning he couldn't get out of bed because his back 'was killing him', while the

\footnotetext{
${ }^{6}$ These three components are referred to in Sanskrit respectively as: manas, buddhi and abamkara and are handled more elaborately in Iyengar (2005), Feuerstein (2001) and Schweizer (1993).

7 This I-maker is according to Iyengar is the part of 'mind' that creates our identification "with me, with my singularity and difference from you, my apartness, my feeling... of being at the center of everything" (2005, pp. $117-$ 118).

8 The eight limbs of yoga are: yama, niyama (concerned with morality), asana, pranayama (postures and breath practices), pratyahara, dharana, dhyana, samadhi (all meditational phases manifesting increasing concentration) (Patanjali's yogasutra II.29).
} 
illustration of Karen is, in fact, showing her as the teacher of a beginning yoga class. She is performing the posture very cautiously in order to teach her students Iyengar's first lesson: to listen to body as subject. Though we clearly cannot experience what exactly Joe sensed while practicing, it is highly probable that he felt unease or even pain coming into the posture, yet he was not listening to these bodily sensations. Why would he not listen to his body? There could be a number of reasons for this. It is possible that Joe was trying to imitate a fellow practitioner, or even his own teacher. He was thus transforming the practice into a competition with fellow students. Perhaps he may have pushed himself in order to feel as if he were an accomplished practitioner. Maybe he was only interested in becoming more flexible. Any one of these possibilities implies that Joe was not practicing properly, at least according to Iyengar's teaching. An interpretation of Iyengar's application of the terms 'mind', 'body', 'subject', 'object' and 'brain' will assist me in explaining Joe's misapprehension of practice as he fails to turn the 'body' into subject.

When describing certain postures, Iyengar refers to a specific organ as 'the brain of the posture'. Thus, the 'body' is portrayed as a potential-brain, fulfilled by organs of choice that corresponds with the specific needs of a certain posture: "in each asana [posture], a specific part of your body is the 'brain' of

the pose. For instance, the outstretched arm is the 'brain' of Utthita Parsvakonasa

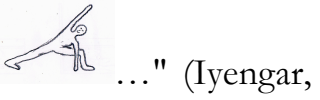
2008 , p. 65). If Iyengar would now be teaching this posture, he would give very technical instructions on how to enter the posture physically. He would direct the practitioner to focal points within the body that when tended to appropriately, yield proper alignment. In the case of the latter posture seen in the illustration, the outstretched right arm would be such point. It would be a 'brain' since, once we give it full attention, it becomes the center from which the whole body is tuned and aligned. If I tend to this elbow, this would involve elongating the arm and the forearm. This will require tending to the shoulder as that is where the arm begins. I will then have to relax this shoulder, yet maintain its clear relation to the shoulder-blade and the spine. From there I would move to the pelvis, the hips, knees, shins, feet in somewhat of a 'mindful chain reaction'. The consideration of beginning this 'mindful chain reaction' in the elbow is a consequence of Iyengar's self-research conducted through decades of practice. Tending to the elbow as 'brain' does not mean that other organs are less important; it is, rather, Iyengar's prudent conclusion that the elbow would be a good source from which to tune the whole body. When one becomes accustomed to practice in such way, the 'body' learns to yield to this 'mindful chain reaction' described. Iyengar's 'bodily brains' should be the source from which practice is conducted. They become the source in the sense that, once the verbal injunction points our awareness to them, 'embodied mindfulness' is initiated towards the 'mindful chain reaction' described. It begins with the specific 'bodilybrain' appropriate to the specific posture and unfolds throughout the body.

The premise of 'embodied mindfulness', conceived within a Cartesian dualism, is that the experience of 'body' (sensations) is a more faithful representation of the present moment than 'mind' (thoughts). Sensations as such do not frame experience within concepts. They do not critique it nor judge it. Once 'cargo' is added to these bodily experiences, such as 'I bet my posture looks good now...', one can detect the interference of an I-maker. This marks the parting from the present moment, experienced as such, to the idiosyncratic appropriation of experience. If I sense pain in my hamstrings, for example, 'body' tells me to back off. The less I frame this sensation within a preconfigured conceptual system, the more I can truly sense its realness, as it is. Concomitantly, this subtlety can be met by a corresponding adjustment. Experiencing this pain, I may indeed follow the body's injunction, or I may think "oh, I'll 'tough this one out' and become more flexible," or "perhaps if I 'tough this out' the teacher will appreciate me more". Yet, to what end would I want this flexibility? Perhaps that would be following thoughts concerned with my body-image or with my over-perfectionism? That would not have much to do with my concrete 'bodily' present experience. It would rather be a manifestation of the I-maker projecting thoughts towards a certain future in order to form a satisfying 'identity'. My developing skill in spotting these supposedly benign issues is a manifestation of embodying Iyengar's 'first lesson of yoga'. It is the lesson of remaining present, established in 'embodied mindfulness', and in 'body' as subject.

By way of summary, 'body-oriented pedagogy' initiates by instructions that lead us to a posture as in the following example of mountain pose : "stand with your feet shoulder-width apart, place your hands to the side of the body, inhale slowly, exhale, relax the shoulders, fix your gaze at eye level towards a point at the horizon...." These instructions are oriented towards our 'body'. Following these initial physical instructions, our 'body' responds with various sensations. Perhaps pain or overstretching is 
experienced. The 'body' corrects itself, relaxes into the pose. It learns to tell 'right' from 'wrong' by the process of trial and error guided by 'embodied mindfulness'. 'Right' or 'wrong' are tentative. What is 'right' for today may be 'wrong' tomorrow. It is only if the 'higher mind' permeates 'body' discerning between pain of over-stretching, memory of a past injury, frailty, excess, under-stretching and a host of other possibilities, that one can cultivate sensitivity to this 'bodily' discernment. Misinterpretations will be experienced as an aching back, knee, or any other organ falling prey to the combination of 'lower mind' and I-maker at the expense of 'higher mind.' Remaining in the posture, for example, the practitioner may experience a host of thoughts. Some may be friendly, encouraging him to ask whether he is mindful to the 'body'. Some may push her over her limits. Some will tell him that today is not a good day to practice, or that she should skip this 'difficult' posture. It is quite difficult to tell which of these thoughts to act upon if the answer is sought only within the closed circle of these thoughts. Yet, if the practitioner re-establishes 'embodied mindfulness' and lets the 'body' become subject, much of this 'talk' resolves and dissolves within pre-conceptual knowing. This knowing is a growing experience of what feels 'right' rooted in the application of 'embodied mindfulness' as the vehicle for this exploration. ${ }^{9}$

As I have illustrated, 'body-oriented pedagogy' seeks to incite 'embodied mindfulness'. 'Embodied mindfulness' in turn yields 'education towards and in presence', as I now show. Let me shortly address this point, which requires that we shift our gaze from how we learn from the body, which is the focus of this article, to tending succinctly to what can be learned through 'body-oriented pedagogy'. This will shed some light on the possible contribution of such pedagogy to contemporary schooling; a theme which surely deserves elaboration in future work.

The more attuned I learn to become, the more I can respond to my surroundings in a matter-offact fashion. I become less prone to emotional turmoil, as I am able to distinguish between the realm of presence within 'body', and the thoughts which reflect the 'lower mind' and the I-maker's interpretation of the experience of the 'body.' For example, if I am required to speak in public, I may panic. Where does this panic emerge from? One may assume that it has to do with being occupied with the outcome of my talk. What if I start stuttering? What if they notice how tense I am? Or, if I do this wrong, I will not get this job...? If all I can do within this experience is dwell in such thoughts, that would literally be 'living as a thinking thing'. Yet, having trained my ability to shift to 'body' in 'embodied mindfulness', I may explore what this panic is before the word panic was thrown by 'lower mind' and I-maker to characterize my embodied state. Perhaps the word itself induces a reverberation that only confuses me further? Mindfully turning my awareness to 'body', I may encounter various sensations: tension in the stomach, perspiration, an accelerated pulse, trembling, heat, and so forth. I observe these without giving them a name. I try to even avoid saying to myself 'my heart is beating quickly', which would soon become 'oh my, my heart is beating quickly' and then 'I can't do this...'. I remain with the pulse itself, without even calling it 'pulse'. Experiencing these sensations, panic, as a 'mind'-derived concept, is broken down to its makings within 'body'. My experience shifts from the realm of thoughts, names and conceptualizations to the realm of sensations. 'Panic' dissolves into a pre-conceptual experience of sensations which, based on my training, remain non-conceptualized sensations. It is no more an entanglement with the future outcome of my public talk, which may be the reason why I sense these sensations in the first place. It becomes a pre-conceptual present experience of sensations. Within this pre-conceptual present moment the shadow of an unknown future evaporates. If I manage to stay with these sensations, the bubble of thoughts deflates. I am certainly not claiming that these sensations are pleasant; however, they ground me in presence, without naming the present in ways that are not necessarily trustworthy and certainly not helpful in this case. By turning to 'body', I may realize that panic is a word that summarizes numerous episodes within my life that are never quite the same. Perhaps they are never quite panic, but rather a host of sensations I may be wise to refrain from naming. This process of 'education in presence' through 'Body-oriented pedagogy' thus cultivates the discernment which allows me to choose. Whether to panic or not, becomes a matter of choice, not a necessity.

There is clearly much more to be said in regard to what we can learn from 'body-oriented pedagogy' as it yields 'education in presence'. I refrain from developing this further at this point due to the scope of this paper and turn now to the final topic that zooms out to the social domain. Here I reflect briefly on the advantages and disadvantages of considering 'body-oriented pedagogy' as 'spiritual' or 'non-spiritual'.

\footnotetext{
9 This conception of "what feels right" is elaborated in breadth in Ergas (forthcoming) as I explain how integrity can be developed through standing meditation.
} 


\section{Should 'Body-Oriented Pedagogy' Be Framed as 'Spiritual'?}

Wexler (2000), Alexander (2001), and Heelas \& Woodhead (2005) have each in their own way pointed to a 'spiritual awakening' characterizing the social climate of the passing decades, and the growing interest in contemplative practice. Given that the sources of 'body-oriented pedagogy' within Eastern paths are often viewed as spiritual/religious, it would seem tempting to locate such pedagogy within a 'spiritual curriculum'. In the following I will not directly handle the definition of 'spirituality'. My intention is mostly to discuss the appropriateness of such framing, some of its pitfalls and some of its advantages, specifically in regard to 'body-oriented pedagogy'.

The first point I make is that framing 'body-oriented pedagogy' within a term such as 'spirituality' may defy the nature of the practice, and may also be a source for hindering proper practice. I make this claim without getting into defining 'spirituality' as a "slippery term" (Alexander, 2001) for I begin by questioning the validity of forcing words over a practice that seeks to remain at the pre-conceptual level of sensations. The great Zen master Shunryu Suzuki (1999), described the practice of Zen meditation and taught his disciples to stick with bare practice and refrain from its grading, naming or conceptualization. Though these are natural tendencies manifesting the very nature of 'mind', they are alien to the way in which I suggested body-oriented-ness. Within the non-discursive realm of sensation, conceptualizations such as 'spiritual' or 'non-spiritual' are simply out of place. 'Body-oriented pedagogy' turns one to gaze at the sensual experience, rather than to its representation through words. In this respect, 'body-oriented pedagogy', being itself a concept, is no more than an injunction to remain within sensations, rather than leap to a habitual judgment and categorization "game". That is, I chose to highlight the present-dwelling in body, rather than a possible spiritual truth (any way defined) that such practice may or may not invoke in the future. Categorizing the pedagogy as spiritual, any way defined, would be committing to outcomes that may be plausible yet have not been developed here.

A second problem arises when considering that framing the practice as 'spiritual' may imply that our 'mind' has tricked us again by 'meriting' us with yet another 'lofty' (and fictitious) identity from which yet more 'I-maker' thoughts emerge. In line with the Tibetan monk Trungpa (1973/2002), I maintain that it is once we begin to sort the practice into such categories, that it may become less authentic. On top of our 'usual' problems we may now identify ourselves as smug 'spiritual'-seekers only to discover years later that this new identification has derailed us from the simple present pre-conceptual bodily-sensed moment.

Notwithstanding, there are some ways in which certain framings whether 'spiritual' or 'nonspiritual' may become advantageous, given the above reservations. That is, given an understanding that these framings are not part and parcel of the practice, but rather an external assessment of its placement within an individual or a community's life. Thus I elaborate two such advantages: 1 ) At the personal level, if a certain framing becomes an additional motivation for practice. That is, for example, if one thinks of an engagement in 'body-oriented pedagogy' as invoking a different mode of perception, 'other' than what he takes to be his ordinary day-to-day living, and this conception serves as an incentive to practice 'bodyoriented pedagogy' then that would seem to me a pragmatic use of the term. Mutatis mutandis, such a conception lends itself to both 'spiritual' and 'non-spiritual' inclinations. 2) At the public level, if framing 'body-oriented pedagogy' serves its incorporation within a 'spiritual' or 'non-spiritual' curriculum. 'Bodyoriented pedagogy' as it was conceived in this article is flexible enough to allow for some conceptions of both 'spiritual' and 'non-spiritual' curricula. Considering the yogic path as one source for 'body-oriented pedagogy', as a 'spiritual' path lends itself directly to be considered within a 'spiritual curriculum'. At the same time, dwelling in 'embodied mindfulness' allows us to frame this as a psycho-physical practice with no spiritual pretentions whatsoever, perhaps even doing away with the "game" of framings as such, as I suggested above. The question, then, is not whether 'body-oriented pedagogy' can be framed as 'spiritual' or 'non-spiritual', for both are possible. It is rather a pragmatic question concerning what represents the best tradeoff in any particular case. For reasons of scope, I cannot consider the pedagogical tradeoffs in this case as in questioning how 'body-oriented pedagogy' may or may not be colored by such framings. Here I will only suggest that the consideration whether the term 'spiritual', 'non-spiritual', or 'secular' should be applied in regards to 'body-oriented pedagogy' remains external to the practice itself. Acknowledged as such, it should be determined by asking which framing increases the chances of incorporating the practice in a certain school given the spiritual/non-spiritual/secular tendencies of the community involved. My point in this article was to articulate a possible educational potential inherent in 
reversing the Cartesian hierarchy and thus to serve the opening for a 'body-oriented pedagogy'. If this argument has been successfully made, then the potential audience's spiritual/secular inclinations should determine the rhetoric applied given loyalty to the principles of the pedagogy as described. Once the pedagogy is practiced, dwelling in the body will not allow that much leeway to stray into framings that are unaccounted for. That is, if we keep reminding ourselves of a fundamental inappropriateness of concepts applied to a pedagogy that teaches us to dwell in the pre-conceptual.

\section{Concluding Thoughts}

This article conceptualized 'body-oriented pedagogy' as it emerges from Iyengar's interpretation of yogaposture practice embedded in classical yoga philosophy. 'Body-oriented pedagogy' suggests a radical reversal of a traditional privileging of 'mind' over 'body' characterizing the Platonic-Cartesian dualistic legacy. The pedagogy turns our gaze to perception through 'body'. Remaining in 'body' within 'embodied mindfulness', 'mind' cannot keep its constant appropriation of experience according to its fancy. By this privileging of sensations over thoughts 'education in and towards presence' emerges to cultivate our ability to finally choose what we are doing, rather than have old habits choose our actions for us.

'Body-oriented pedagogy' takes refuge in the very 'body' that Descartes deemed untrustworthy. It is rather our 'mind' ('lower mind' and I-maker) that should be doubted, not 'body' (as 'higher mind' permeating the whole 'body'). Through 'embodied mindfulness', we cultivate the ability to discern when to trust our thoughts and when to disassociate from them, for they are not necessarily a truthful expression of who we are. Thus, we place 'Descartes in a headstand' in order to suggest a complementary form of 'education in and towards presence.' However, we need Descartes back on his feet as well, for we need our 'minds' as rational thinkers. Returning to the example of the public talk to be given, once I regain my equilibrium and panic may have resided, I will now need to communicate with the audience in a coherent fashion. 'Body-oriented pedagogy' does not teach this skill directly. That is the realm of a 'mindoriented pedagogy' commonly practiced in contemporary schooling; a pedagogy that trains one in and through thoughts. Yet, developing this claim further cannot be handled here, as well as many other questions concerning the application of such pedagogy. We may ask, for example, whether 'body-oriented pedagogy' can be applied within more conventional disciplinary learning? Can history or mathematics, for example, incorporate 'body' into their pedagogy? The yogic posture was suggested here as one form of 'body-oriented pedagogy'. I am quite sure the theory developed can be applied to other 'bodily-oriented' practices such as martial arts and perhaps physical education. This raises the question: what forms of 'body-oriented pedagogy' are feasible within school setting: yogic postures, taiqi, Aikido...? How can we train teachers towards such diverse curricula? Is 'body-oriented pedagogy' appropriate to all ages? To all students? Stemming from the centrality of 'body', the paper suggested some pitfalls involved in framing 'body-oriented pedagogy' within categories such as 'spiritual' or 'non-spiritual'. However, once the pedagogy finds a home, it may be colored by certain 'spiritual' or 'secular' framings. Would such framings not color the pedagogy, despite an attempt to adhere to its 'body-oriented-ness'? These are but few questions yet to be addressed. We may need to stand on our hands, on our legs and on our heads in order to respond to them through presence.

\section{Acknowledgment}

The author wishes to acknowledge the reviewers of this paper and the editors of this journal for their insightful suggestions and careful reading.

\section{References}

Alexander, H. A. (2001). Reclaiming goodness. Indiana: University of Notre Dame Press.

Bruner, J (1960) The process of education. Cambridge, MA: Harvard University Press.

Davidson, R. J., Kabat-Zinn, J., Schumacher, J., Rosenkranz, M., Muller, D., Santorelli, S., (2003). Alterations in brain and immune function produced by mindfulness meditation. Psychosomatic Medicine, 65, 564-570. 
Descartes, R. (1988). Meditations. In J. Cottingham, R. Stoothoff \& D. Murdoch (Trans. and Eds.). Descartes selected philosophical writings. Wiltshire, MA: Cambridge University Press.

Dewey, J. (1916). Democracy and education. New York: The MacMillan Company.

De Michelis, E. (2004). A bistory of modern yoga. New York: Continuum.

Eisner, E.W. (1993). Forms of understanding and future of educational research. Educational Researcher, 22(7), 5-11.

Eliade, M. (1969/2009). Yoga immortality and freedom. Princeton: Princeton University Press.

Ergas, O. (forthcoming). Re-envisioning embodied higher education towards Integrity: Standing meditation as pedagogy. In J. Lin, R. Oxford, E. Brantmeier (Eds.), Re-envisioning higher education: Embodied paths to wisdom and social transformation. Information Age Publishing.

Eppert, C., \& Wang, H. (2008) Cross-cultural studies in curriculum: Eastern thought, educational insights. New York: Lawrence Erlbaum Associates.

Feuerstein, G. (2001). The yoga tradition. Prescot, Arizona: Hohm Press.

Flook, L. et al. (2010). Effects of mindful awareness practices on executive functions in elementary school children. Journal of Applied School Psychology, 26, 70-95.

Heelas, P. \& Woodhead, L. (2005). The spiritual revolution. Oxford: Blackwell Publishing.

Iyengar, B.K.S. (1993). Light on the yoga sutras of patanjali. Suffolk: Thorsons.

Iyengar, B.K.S. (2002). The tree of yoga. Boston: Shambhala.

Iyengar, B.K.S. (2005). Light on life. Rodale: Chatham.

Iyengar, B.K.S. (2008). Yoga the path to holistic health. London: Dorling Kindersley Limited.

Johnson, W. (2000). Aligned, relaxed, resilient: The physical foundations of mindfulness. Boston: Shambhala.

Kabat-Zinn, J. (2005). Coming to our senses. New York: Hyperion.

Miller, J. (2007). The holistic education curriculum review (2nd ed.). Toronto: University of Toronto Press.

Napoli, M., Krech, P.R., Holly, L.C. (2005). Mindfulness training for elementary school students: The attention academy. Journal of Applied School Psychology, 21(1), 99-125.

Schweizer, P. (1993). Mind/Consciousness dualism in sāmkhya-yoga philosophy. Philosophy and Phenomenological Research, 53(4), 845-859.

Shusterman, R. (2008). Body consciousness. Cambridge: Cambridge University Press.

Suzuki, S. (1999). Zen mind, beginner's mind. New York: Wheatherhill.

Trungpa, C. (1973/2002). Cutting through spiritual materialism. Boston: Shambhala.

Vokey, D. (2001) Longing to connect: Spirituality in public schools. Paideusis, 13(2), 23-41.

Wexler, P. (2000). The mystical society. Boulder: Westview press.

\section{About the Author}

Dr. Ergas is a lecturer at the Hebrew University of Jerusalem, his research interests lie in the conceptualization of contemplative practice as education. He focuses on pedagogical aspects of mindfulness, yoga, tai chi and standing meditation attempting to unravel the educational process invoked by these practices as grounded in their sources. His research methodology involves phenomenology, autoethnography, contemplative inquiry and narrative research. 